\title{
Subfunctionalization of peroxisome proliferator response elements accounts for retention of duplicated fabp 1 genes in zebrafish
}

Robert B. Laprairie ${ }^{1}$, Eileen M. Denovan-Wright ${ }^{1}$ and Jonathan M. Wright ${ }^{2^{*}}$

\begin{abstract}
Background: In the duplication-degeneration-complementation (DDC) model, a duplicated gene has three possible fates: it may lose functionality through the accumulation of mutations (nonfunctionalization), acquire a new function (neofunctionalization), or each duplicate gene may retain a subset of functions of the ancestral gene (subfunctionalization). The role that promoter evolution plays in retention of duplicated genes in eukaryotic genomes is not well understood. Fatty acid-binding proteins (Fabp) belong to a multigene family that are highly conserved in sequence and function, but differ in their gene regulation, suggesting selective pressure is exerted via regulatory elements in the promoter.
\end{abstract}

Results: In this study, we describe the PPAR regulation of zebrafish fabp 1a, fabp 1b.1, and fabp 16.2 promoters and compare them to the PPAR regulation of the spotted gar fabp 1 promoter, representative of the ancestral fabp 1 gene. Evolution of the fabp 1 promoter was inferred by sequence analysis, and differential PPAR-agonist activation of fabp 1 promoter activity in zebrafish liver and intestine explant cells, and in HEK293A cells transiently transfected with wild-type and mutated fabp 1promoter-reporter gene constructs. The promoter activity of spotted gar fabp 1, representative of the ancestral fabp 1, was induced by both PPARa- and PPARY-specific agonists, but displayed a biphasic response to PPARa activation. Zebrafish fabpla was PPARa-selective, fabp 16.1 was PPAR $y$-selective, and fabp 16.2 was not regulated by PPAR.

Conclusions: The zebrafish fabp 1 promoters underwent two successive rounds of subfunctionalization with respect to PPAR regulation leading to retention of three zebrafish fabp 1 genes with stimuli-specific regulation. Using a pharmacological approach, we demonstrated here the divergent regulation of the zebrafish fabp 1a, fabp 1b.1, and fabp 1b.2 with regard to subfunctionalization of PPAR regulation following two rounds of gene duplication.

Keywords: Peroxisome proliferator activated receptor (PPAR), Dual luciferase assay, Fatty acid-binding protein, Subfunctionalization, Neofunctionalization, Nonfunctionalization, Teleost fishes, Gene promoter evolution, Zebrafish, Spotted gar

\footnotetext{
* Correspondence: jmwright@dal.ca

${ }^{2}$ Department of Biology, Dalhousie University, 31355 Oxford St, PO Box

15000, Halifax, NS B3H 4R2, Canada

Full list of author information is available at the end of the article
} 


\section{Background}

Gene duplication is thought to facilitate increasing organismal complexity, but evolution does not accommodate redundancy. Duplication of genes can occur by unequal crossing-over during meiosis, replication slippage, retrotransposition, aneuploidy, or whole genome duplication [1]. The common fate of duplicated genes is loss of one copy owing to accumulated mutation and functional decay (non-functionalization) [2, 3]. Alternatively, both copies of a duplicated gene may be retained if one of the duplicates acquires a novel function (neofunctionalization), or the functions of the ancestral gene are subdivided between the duplicates (subfunctionalization) [2-4]. Non-, neo-, and sub-functionalization represent three possible fates of duplicated genes as described in the duplication degeneration complementation (DDC) model [2]. Both mutation of protein coding regions and the loss or gain of cis-acting regulatory elements in the promoters of duplicated genes may account for altered function of duplicated genes. Mutations in regulatory elements of promoters may affect tissue-, developmental stage- and stimulus-dependent transcript levels of duplicated genes [2-5].

Fatty acid binding proteins (Fabp), which belong to the multigene family of intracellular lipid-binding proteins, function as carriers of fatty acids, eicosanoids and other hydrophobic ligands to effectors in the cytosol and nucleus [6]. Previously, we observed that the promoters of the tandemly duplicated fabp genes of zebrafish, fabp $1 b .1$ and $f a b p 1 b .2$, differ in their regulation by peroxisome proliferator activated receptors (PPARs), where fabp $1 b .1$ promoter activity was induced by PPAR, but fabp $1 b .2$ promoter activity was not induced by PPAR [7]. The zebrafish fabpla and fabp1b genes were generated by duplication of ancestral $f a b p 1$ gene owing to a whole genome duplication (WGD) event that occurred in the ray-finned teleost lineage approximately 325 mya [8-11]. Subsequently, the zebrafish fabp $1 b .1$ and fabp $1 b .2$ genes arose by tandem duplication of fabp $1 b$, most likely by misaligned cross-over of homologous chromosomes during meiosis [12-14]. The zebrafish fabp $1 b .1$ and $f a b p 1 b .2$ genes are the only tandem duplicates of the multigene family of intracellular lipid-binding protein genes identified, thus far, in teleost fishes [12]. As a result, the zebrafish genome contains three extant fabp1 genes, fabp $1 a, f a b p 1 b .1$, and fabp1b.2. Spotted gar (Lepisosteus oculatus, order Lepisosteiformes) belongs to an order of teleost fishes that did not undergo a WGD, therefore, its genome contains a single copy of the fabp 1 gene.

Zebrafish fabp $1 b .1$ and fabp $1 b .2$ differ in their responsiveness to dietary fatty acids: fabp $1 b .1$ mRNA levels are increased in the intestine of linolenic acid-fed zebrafish, whereas fabp1b.2 mRNA levels are unaffected by linolenic acid [14]. Zebrafish fabpla, fabp1b.1, and fabp1b.2 also differ in their responsiveness to the nonselective PPAR agonist, clofibrate [15]. fabpla mRNA levels are increased in the liver of clofibrate-fed zebrafish, fabp $1 b .1$ mRNA levels are increased in the heart of clofibrate-fed zebrafish, while fabp $1 b .2$ mRNA levels are unaffected by clofibrate [15]. These findings implicate the PPARs in the differential regulation of the fabpla, fabp $1 b .1$ and fabp $1 b .2$ genes in zebrafish [14, 15].

PPARs are nuclear receptor transcription factors that bind, and are activated by, free fatty acids and eicosanoids [16-18]. Upon activation, PPARs heterodimerize with the retinoid $\mathrm{X}$ receptor (RXR) and bind to a PPAR response element (PPRE) located in the promoters of many vertebrate genes, including fabp genes [16-18]. The consensus sequence for the vertebrate PPRE is defined as 5' ${ }^{\prime}$-CAAAACAGGTCANAGGTCA-3' [16-18]. Binding of the PPAR to a PPRE may cause increased or decreased gene expression, depending on the gene [16-18]. Three PPAR isoforms have been identified across vertebrate species: PPAR $\alpha$, PPAR $\gamma$, and PPARß/ $\partial$ [16-18]. While PPAR $\alpha$ and PPAR $\gamma$ are expressed in

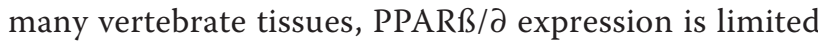
to the skin, adipose, and brain [16-18]. A PPRE may be PPAR isoform-selective (i.e., a PPRE that preferentially binds PPAR $\alpha$ relative to PPAR $\gamma$ ) $[16,17]$. A PPRE with high sequence identity in the $5^{\prime}$ flanking region (5' FR) (underlined: 5' -CAAAACAGGTCANAGGTCA-3') to the consensus PPR exhibits greater activation of transcription at promoters by the isoform PPAR $\alpha$ compared to the isoform PPAR $\gamma$, whereas PPAR $\gamma$ binding is lessdependent on the 5'FR than PPAR $\alpha$ [16-18]. Both PPAR $\alpha$ and PPAR $\gamma$ bind to the direct repeat element (DR1) (underlined 5'-CAAAACAGGTCANAGGTCA-3') of the PPRE to activate transcription [16-18]. A PPRE with low sequence identity in the 5'FR and high sequence identity in the DR1, therefore, may be PPAR $\gamma$-selective [16-18], as is apparent for fabp $1 b .1$ promoter activity, which displays PPAR $\gamma$-selectivity in liver and intestine explant tissue and fabp promoter-reporter gene constructs in the human embryonic kidney cells, HEK293A [7].

The objective of this study was to investigate divergent, PPAR-dependent transcriptional regulation at the promoters of the zebrafish (Danio rerio) fabpla, fabp $1 b .1$ and fabp $1 b .2$ genes, and the spotted gar fabp 1 gene (representative of the ancestral $f a b p 1$ gene) in order to determine the molecular mechanisms that led to the retention of the three $f a b p$ genes in zebrafish following the teleostspecific WGD event and subsequent local (tandem) duplication event. To define teleost fabp1 promoter evolution, the regulation of zebrafish fabpla, fabp 1b.1, and fabp $1 b .2$ gene promoters was investigated by three approaches: (1) assay of gene transcripts in liver and intestine explant cultures treated with PPAR-agonists; (2) identification of 
putative PPREs in the zebrafish fabp 1a, fabp 1b.1, and fabp $1 b$. and the spotted gar fabpl promoters by in silico analysis; and (3) in HEK293A cells using wild-type and mutagenized zebrafish fabpla, fabp 1b.1, and fabp1b.2, and spotted gar fabpl promoters fused to the luciferase reporter gene, to determine the promoter-specific regulation of fabpl genes by PPAR $\alpha$ and PPAR $\gamma$. We applied a comparative pharmacological approach to spotted gar fabp 1 and zebrafish fabpla, fabp 1b.1, and fabp $1 \mathrm{~b} .2$ promoter activity across a wide range of PPAR agonist concentrations in the absence or presence of PPAR antagonists. In this way, it was possible to model evolutionary processes for PPAR isoformselectivity through readily quantifiable measurements of agonist potency, efficacy, and specificity.

\section{Results}

Differential induction of zebrafish fabp $1 a$, fabp $1 b .1$ and fabp 16.2 transcription by PPAR agonists in zebrafish liver and intestine explant culture

The genomic organization of the fabp 1 gene of spotted gar and, the fabpla, fabp $1 b .1$ and fabp $1 b .2$ genes of zebrafish is highly conserved; each gene consists of four exons, they share between $57-75 \%$ mRNA sequence identity (Fig. 1a) and $40-71 \%$ amino acid sequence identity (Fig. 1b), but differ markedly in their promoter sequences (Fig. 1c). The duplicated zebrafish fabp1 genes also exhibit differential regulation by linolenic acid and by the PPAR-agonist, clofibrate $[12,14,16]$.

To determine if fabpla, fabp $1 b .1$ and fabp $1 b .2$ mRNA levels are induced by PPAR activation, the steady-state levels of duplicated fabp transcript were quantified in explant tissue derived from zebrafish liver and intestine treated with the PPAR $\alpha$ agonist, WY14,643, or the PPAR $\gamma$ agonist, rosiglitazone. fabpla mRNA transcripts were detected in both liver and intestine. The PPAR $\alpha$ agonist, WY14,643, increased fabp1a transcript levels 109-fold, while the PPAR $\gamma$ agonist, rosiglitazone, increased fabpla transcript levels 60-fold. Induction of fabpla transcriptional initiation by PPAR agonists was only in intestine explant tissue and not in liver explant tissue (Fig. 2). Transcriptional induction of the zebrafish fabpla, therefore, appeared to be PPAR $\alpha$-selective as WY14643 resulted in higher fabpla mRNA levels than rosiglitazone treatment (Fig. 2). fabp1b.1 mRNA levels were increased 13-fold following WY14643 treatment, and 26-fold following rosiglitazone treatment in liver, but not intestine (Fig. 2). Based on the differential regulation of these duplicated genes by PPAR agonists, fabp1b.1 induction appears PPAR $\gamma$-selective as rosiglitazone treatment resulted in higher fabp $1 b .1$ mRNA levels than WY14643 treatment (Fig. 2). fabp1b.2 mRNA was detected in both liver and intestine, but the steady-state level of fabp1b.2 transcripts was not changed in liver or intestine explant tissue by either rosiglitazone or WY14643

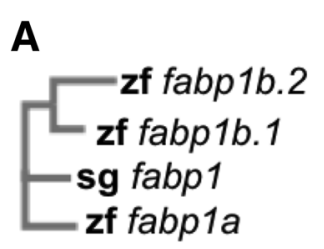

B

\begin{tabular}{c|cccc} 
& fabp1 & fabp1a & fabp1b.1 fabp1b.2 \\
\hline fabp1 & 100 & & & \\
fabp1a & 71 & 100 & & \\
fabp1b.1 & 69 & 66 & 100 & \\
fabp1b.2 & 58 & 57 & 75 & 100
\end{tabular}

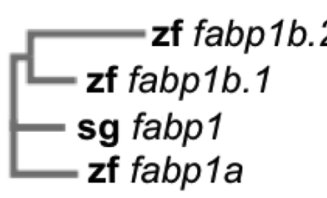

C

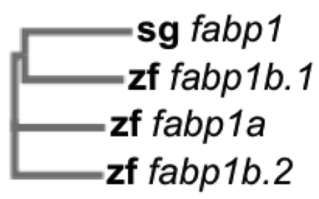

\begin{tabular}{c|cccc} 
& fabp1 & fabp1a & fabp1b.1 fabp1b.2 \\
\hline fabp1 & $\mathbf{1 0 0}$ & & & \\
fabp1a & 37 & 100 & & \\
fabp1b.1 & 36 & 37 & 100 & \\
fabp1b.2 & 37 & 46 & 41 & 100
\end{tabular}

Fig. 1 Cladograms and comparisons of sequence identity for spotted gar fabpl and zebrafish fabpla, fabp 1b.1, and fabp 1b.2 mRNA (a), amino acid (b), and promoter (c) sequences. Multiple sequence alignments were conducted using Clustal Omega with default settings. Cladograms of multiple sequence alignments are shown on the left ( $\mathrm{z}=$ zebrafish, sg=spotted gar). Tables shown on the right display percent sequence identity between genes. Accession files were: fabp 1 mRNA: XM_006626498, amino acid: XP_006626561, promoter: Gene ID: 102694982; fabp1a mRNA: NM_001044712, amino acid: NP_001038177, promoter: Gene ID: 791610; fabp1b.1 mRNA: NM_001024651, amino acid: NP_001019822, promoter: Gene ID: 554095; fabp 1b.2 mRNA: XM_002663048, amino acid: XP_002663094, promoter: Gene ID: 100330224 from National Center for Biotechnology Information (NCBI) Gene [36] 


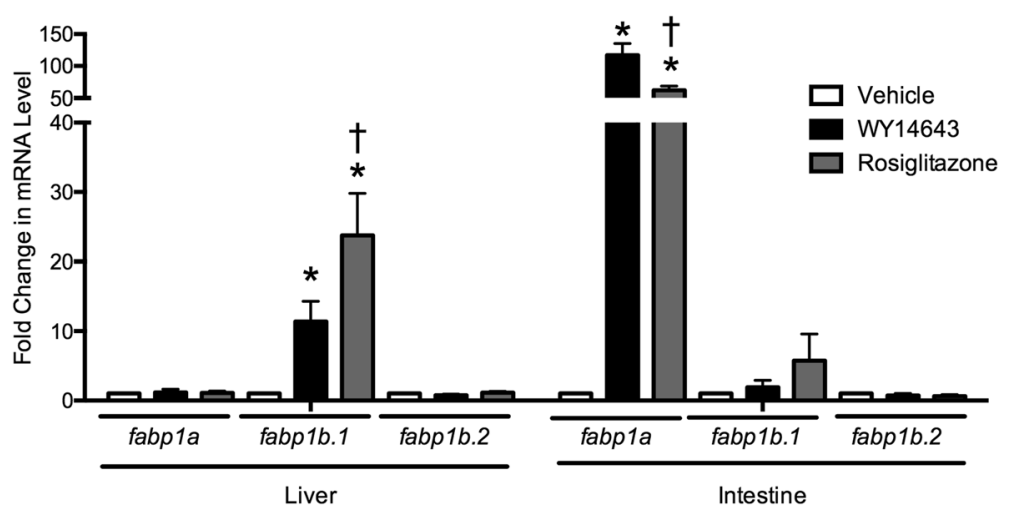

Fig. 2 The PPAR-dependent induction of fabpla and fabp 16.1 mRNA was tissue-specific. Explant liver and intestine cells were cultured for $48 \mathrm{~h}$ before being treated with $1 \mu \mathrm{M}$ WY14643 (PPARa-specific agonist) or rosiglitazone (PPARY-specific agonist) for 24 h. fabp 1a, fabp 1b.1, and fabp 1b.2 mRNA levels were quantified by qRT-PCR using the ${ }^{\Delta \Delta} C T$ method and normalized to GAPDH. Data are mean \pm SEM. ${ }^{*} P<0.001$ compared to vehicle treatment within tissue and transcript, $+P<0.001$ compared to WY14643 treatment within tissue and transcript as determined by two-way ANOVA followed by Bonferroni's post-hoc test. $n=4$

treatment (Fig. 2). These data demonstrate that transcription of fabpla and fabp1b.1, but not fabp1b.2, is induced by PPAR in zebrafish liver and intestine explant tissue.

\section{In silico analyses}

Promoter sequences of the zebrafish fabpla, fabp1b.1, and fabp1b.2, and spotted gar fabp1 genes, 5' of their transcription start sites (TSS), were analyzed in silico for the presence of putative PPREs. Sequences of 3,308 bp for zebrafish fabp1a, 3,059 bp for zebrafish fabp1b.1, 3,218 bp for zebrafish fabp 1b.2, and 3,283 bp spotted gar fabp1 were retrieved from databases using the conserved non-coding sequence (CNS) discovery pipeline (v. 3.0) [19] (Additional file 1) and putative PPREs identified by the algorithm, MatInspector (v. 8.1). The length (in bp) of the promoter fragments retrieved was chosen by the CNS discovery pipeline as the region within 4,000 bp 5' upstream of the TSS containing $>60 \%$ of transcription factor binding motifs with $>60 \%$ sequence identity to the vertebrate transcription factor binding site [19].

Two putative PPREs were identified in the fabpla promoter fragment that had $66.7 \%$ and $87.9 \%$ (indicated by the purple rectangle in Fig. 3) sequence identity to the consensus sequence for the vertebrate PPRE $\left(5^{\prime}-\right.$ $3^{\prime}$, respectively) (Additional file 1) [16, 17]. Five putative PPREs were identified in the fabp $1 b .1$ promoter fragment that exhibited $65 \%, 68.1 \%, 82.3 \%$ (indicated by the red rectangle in Fig. 3), $65.1 \%$ and $76.2 \%$ sequence identity to the consensus sequence for the vertebrate PPRE $\left(5^{\prime}-3^{\prime}\right.$, respectively) (Additional file 1) $[16,17]$. No PPREs were identified within the fabp1b.2 promoter fragment (Additional file 1). The PPRE at $-2,710$ bp relative to the TSS in fabpla displayed high sequence identity to the PPRE consensus in the 5'FR (5'-CAAAAC-3'), but not the DR1 (5'-AGGTCANAGGTCA-3') region of the

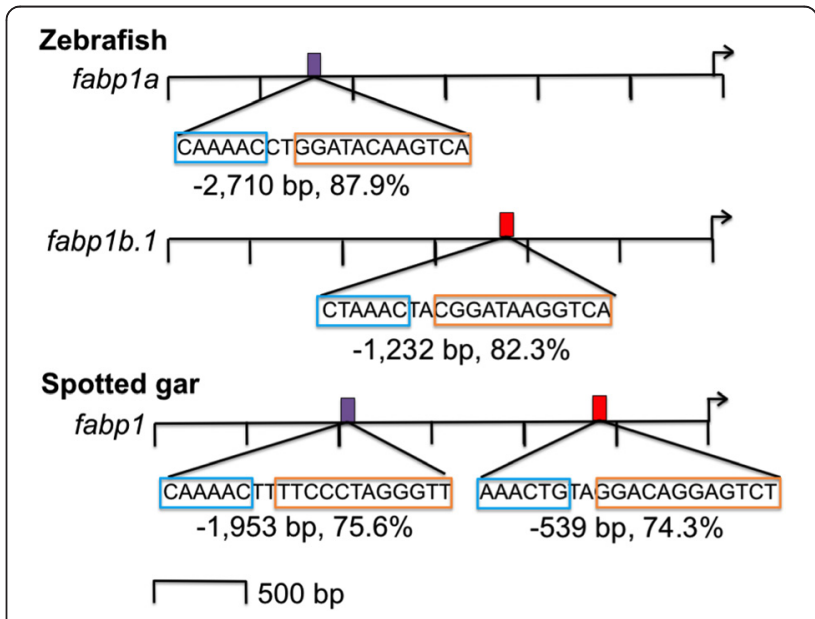

Fig. 3 Putative PPREs in the zebrafish fabpla, fabplb.1 and fabp 1b.2, and spotted gar fabp 1 gene promoters. Putative PPREs were identified using MatInspector (v. 8.1). Approximately 3,000 bp promoter fragments are shown (scale: bars at 500 bp intervals). Right-facing arrows indicate the TSS. Gene name is indicated to the left of each promoter. Coloured rectangles indicate putative PPREs (sequence, position relative to TSS, and \% sequence identity to the defined vertebrate PPRE consensus sequence below each promoter). Purple rectangles indicate PPREs that may be PPARa-selective. Red rectangles indicate PPREs that may be PPARY-selective. Blue boxes indicate the $5^{\prime} F R$. Orange boxes indicate the DR1. A possible PPARaselective PPRE was identified at $-2,710$ bp relative to the TSS of the zebrafish fabp 1a promoter. A possible PPARY-selective PPRE was identified at $-1,232$ bp relative to the TSS of the zebrafish fabp 16.1 promoter. No PPREs were identified in the zebrafish fabp 16.2 promoter. Two putative PPREs were identified at $-1,953$ bp (PPRE-1) and $-539 \mathrm{bp}$ (PPRE-2) relative to the TSS of the spotted gar fabp 1 promoter that were PPARa- and PPARY-selective, respectively. Complete sequence data are provided in Additional file 1 
PPRE (Additional file 1). In contrast, the PPRE sequence at $-1,232$ bp relative to the TSS in fabp $1 b .1$ displayed high sequence identity to the vertebrate PPRE consensus in the DR1, but not 5'FR (Additional file 1). The 5'FR of the PPRE enhances the binding of PPAR $\alpha$ to the PPRE and, thereby, imparts PPAR $\alpha$-selectivity to a PPRE. The 5 ' FR is not required, however, for PPAR $\gamma$ binding to the PPRE and, thus, is not crucial for PPAR $\gamma$-dependent gene regulation $[16,17]$. Based on this observation, the putative PPRE identified at $-2,710$ bp in the fabpla promoter appears to be PPAR $\alpha$-selective, whereas the PPRE at $-1,232$ bp in fabp $1 b .1$ was PPAR $\gamma$-selective, which is consistent with the induction of the steadystate levels of fabp $1 a$ and fabp $1 b .1$ transcripts in zebrafish explant intestine cultures treated with PPAR $\alpha$ - and PPAR $\gamma$-specific agonists (Fig. 2).

Four putative PPREs were identified in the spotted gar fabp 1 promoter that had $75.6 \%$ (indicated by the purple rectangle in Fig. 3), 64.7 \%, 74.3 \% (indicated by the red rectangle in Fig. 3), and $64.8 \%$ sequence identity to the consensus sequence of the vertebrate PPRE $\left(5^{\prime}-3^{\prime}\right.$, respectively). Similar to the PPRE in the zebrafish fabpla gene, the putative PPRE present at $-1,953$ bp relative to the TSS of spotted gar fabpl displayed high sequence identity to the PPRE consensus sequence in the 5'FR (henceforth referred to as PPRE-1). Like the PPRE in zebrafish $f a b p 1 b .1$, the putative PPRE at -539 bp relative to the TSS of spotted gar fabpl displayed high sequence identity to the PPRE consensus in the DR1 region (henceforth referred to as PPRE-2) [16, 17, 20, 21]. Taken together, these data suggest that the spotted gar fabp 1 promoter might be regulated by both PPAR $\alpha$ - and PPAR $\gamma$-selective PPREs $[16,17,20,21]$. Furthermore, these data suggested that the PPREs with preferential binding affinity for PPAR $\alpha$ and PPAR $\gamma$, respectively, in the ancestral (spotted gar) fabp1 gene were subdivided between fabpla and fabp1b.1 subsequent to the WGD event that occurred in ray-finned fish.

\section{Analyses of zebrafish fabp 1a, fabp $1 b .1$ and fabp $1 b .2$ and spotted gar fabp1 promoter activity in HEK293A cells}

To determine functionality of putative PPREs in the fabp $1 a$ and fabp $1 b .1$ promoters, 3,300 bp of fabp $1 a$ and 2,847 bp of $f a b p 1 b .15^{\prime}$ upstream of their respective TSS were PCR-amplified from zebrafish genomic DNA and cloned into the pGL3-Basic promoter-reporter plasmid. In the pGL3-Basic plasmid, the 3,300 bp of fabpla and 2,847 bp of $f a b p 1 b .1$ were fused to the firefly luciferase gene for functional promoter assays. All promoter fragments displayed similar basal promoter activity to the TK promoter in HEK293A cells (data not shown). Treatment of HEK293A cells transfected by the zebrafish fabpla promoter construct with $1 \mathrm{nM}-1 \mathrm{mM}$ WY14643 (PPAR $\alpha$ agonist) for $24 \mathrm{~h}$ induced in fabp1a promoter activity (Fig. 4a). WY14643-dependent fabpla promoter activity was inhibited by the PPAR $\alpha$-selective antagonist GW6471 [rightward shift in the concentrationresponse curve (CRC) and greater $\mathrm{EC}_{50}$ ] (Table 1, Fig. 4a). WY14643-dependent fabpla promoter activity was not inhibited by the PPAR $\gamma$-selective antagonist T0070907 (Table 1, Fig. 4a). Treatment of HEK293A cells transfected with the fabpla promoter construct with $1 \mathrm{nM}-1 \mathrm{mM}$ rosiglitazone (PPAR $\gamma$ agonist) for $24 \mathrm{~h}$ also increased fabpla promoter activity (Fig. 4b). Rosiglitazonedependent fabpla promoter activity was inhibited by T0070907, but not by GW6471 (Table 1, Fig. 4b). WY14643 was a more potent PPAR agonist for induction of fabpla promoter activity than rosiglitazone, indicating the zebrafish fabpla gene contained at least one functional, PPAR $\alpha$-selective, PPRE (Table 1).

Treatment of HEK293A cells transfected by the fabp1b.1 promoter construct with WY14643 induced fabp1b.1 promoter activity (Fig. 4c). WY14643-dependent fabp1b.1 promoter activity was inhibited by GW6471, but not by T0070907 (Table 1, Fig. 4c). Treatment of HEK293A cells transfected by the fabp $1 b .1$ promoter construct with rosiglitazone also increased fabp $1 b .1$ promoter activity (Fig. 4d). Rosiglitazone-induced fabp $1 \mathrm{~b} .1$ promoter activity was inhibited by T0070907, but not by GW6471 (Table 1, Fig. 4d). Rosiglitazone was a more potent agonist of fabp $1 b .1$ promoter activity than WY14643, indicating that the zebrafish fabp $1 b .1$ promoter contained a functional, PPAR $\gamma$-selective PPRE (Table 1$)$. Efficacy $\left(E_{\max }\right)$ did not differ between agonists or promoters. Thus, differences in agonist activity between the fabpla and fabplb.1 promoters were attributed to disparate potencies (i.e. $\mathrm{EC}_{50}$ ) of the PPAR isoforms acting at the fabpla and fabp1b.1 promoter PPREs (Table 1).

Site-directed mutagenesis was used to confirm the functionality of putative PPREs identified in the zebrafish fabpla and fabp $1 b .1$ promoters. Mutagenesis of the 5'FR was expected to reduce the affinity of PPAR $\alpha$ to the PPRE (i.e. a rightward shift in the CRC), whereas mutagenesis of the DR1 was expected to generally reduce PPAR affinity to the promoter [16-18]. The 5'FR and DR1 elements of the fabpla PPRE (-2,710 bp) and the fabp1b.1 PPRE $(-1,232)$ were individually mutagenized (Fig. 5a, b).

Treatment of HEK293A cells transfected by the fabp1a $\Delta 5^{\prime} \mathrm{FR}$ promoter construct with WY14643 shifted the CRC to the right compared to non-mutated fabpla (Table 1, Fig. 5c). Treatment of HEK293A cells transfected with the fabp1a $\triangle \mathrm{DR} 1$ promoter construct with WY14643 shifted the CRC to the right compared to non-mutated fabpla and fabpla $\Delta 5^{\prime}$ FR (Table 1, Fig. 5c). Treatment of HEK293A cells transfected by the fabpla $\triangle 5$ 'FR promoter construct with rosiglitazone shifted the CRC compared to non-mutated fabpla (Table 1, Fig. 5d). 

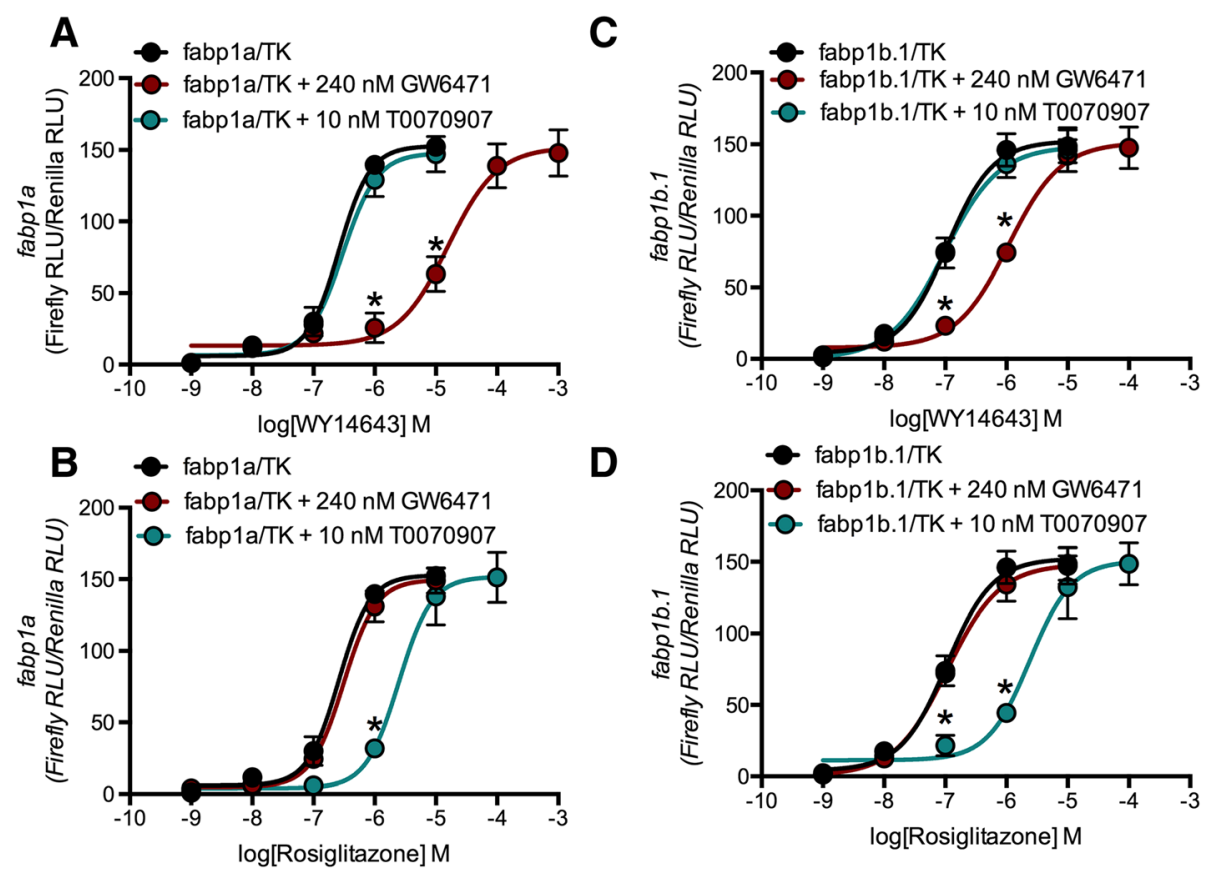

D

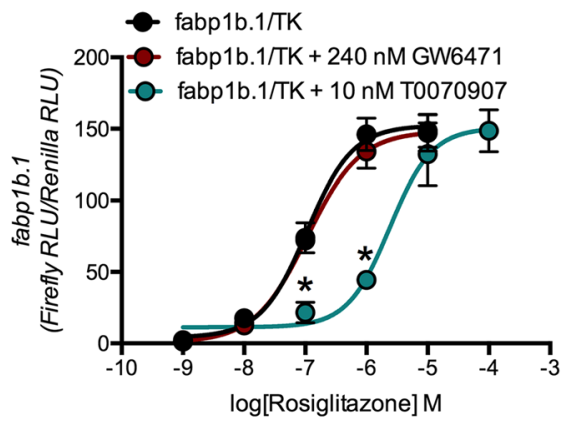

Fig. 4 PPAR antagonism of zebrafish fabpla and fabp 16.1 promoter activity was PPARa- and PPARy-selective, respectively. Firefly luciferase activity driven by the fabpla $(\mathbf{a}, \mathbf{b})$ or fabp 16.1 (c, d) promoters was normalized to Renilla luciferase activity driven by the TK promoter in HEK293A cells treated with $1 \mathrm{nM}-1 \mathrm{mM}$ WY14643 (PPARa agonist) (a, c) or rosiglitazone (PPARy agonist) (b, d) \pm the PPAR antagonists $240 \mathrm{nM}$ GW6471 (PPARa antagonist) or $10 \mathrm{nM}$ T0070907 (PPARy antagonist) for $24 \mathrm{~h}$. Data are mean \pm SD. ${ }^{*} P<0.001$ compared to fabpla/TK or fabp 1b.1/TK alone as determined via one-way ANOVA followed by Bonferroni's post-hoc test. $n=3$

The CRC was shifted to the right in HEK293A cells transfected with the fabpla $\triangle \mathrm{DR} 1$ promoter construct and treated with rosiglitazone compared to non-mutated fabpla and and fabpla $\Delta 5^{\prime}$ FR (Table 1, Fig. 5d). These data demonstrate that the PPRE at $-2,710$ was functional and regulated, in part, by PPAR $\alpha$ as mutagenesis of the 5'FR consistently affected PPAR-dependent induction of promoter activity [17]. Moreover, the DR1 element of the PPRE is required for the binding of all PPARs, a finding further supported by the functionality of the PPRE at $-2,710$ bp of the fabpla promoter fragment [16-18].

WY14643 did not change the CRC for promoter activity in HEK293A cells transfected by the fabp1b.1 $\Delta 5^{\prime} \mathrm{FR}$ promoter construct compared to non-mutated fabp $1 b .1$ promoter construct (Table 1, Fig. 5e). WY14643 treatment shifted the CRC to the right in HEK293A cells transfected by the fabp $1 b .1 \Delta \mathrm{DR} 1$ promoter construct compared to non-mutated fabp $1 b .1$ promoter (Table 1 , Fig. 5e). Although the $\mathrm{EC}_{50}$ was shifted slightly to the right, the rosiglitazone produced a potent and fully efficacious response in HEK293A cells transfected by the fabp1b.1 $\Delta 5^{\prime} \mathrm{FR}$ promoter compared to non-mutated fabp1b.1 promoter (Table 1, Fig. 5f). The rosiglitazone CRC was shifted to the right in HEK293A cells transfected with the fabp1b.1 $\triangle \mathrm{DR} 1$ promoter construct by 2.5 orders of magnitude compared to non-mutated fabp1b.1 promoter (Table 1, Fig. 5e). These observations provide compelling evidence that the zebrafish fabp $1 b .1$ promoter region contains a functional, PPAR $\gamma$-selective PPRE at $-1,232$ bp as rosiglitazone was a more potent agonist of PPAR induction of fabp1b.1 promoter activity than WY14643, and the DR1 element, not the 5'FR, was the major regulator of PPAR potency in these assays (Table 1). Since neither mutagenesis of the 5'FR or DR1 in fabpla or fabp $1 b .1$ abolished transcriptional induction of these fabp genes by PPAR agonism, and no change in $E_{\max }$ was observed, additional, functional PPREs are likely present in both the fabpla and fabp $1 b .1$ promoters.

Given that both fabp $1 a$ and fabp $1 b .1$ promoters contained functional, PPAR subtype-selective PPREs, we assayed the responsiveness of the orthologous spotted gar fabpl gene promoter activity to PPAR isoformspecific agonisism. A 3,283 bp fragment of the spotted gar fabp 1 promoter, $5^{\prime}$ upstream of its TSS, was PCRamplified from spotted gar genomic DNA and cloned into the pGL3-Basic promoter-reporter plasmid $5^{\prime}$ of the firefly luciferase gene. Treatment of HEK293A cells transfected by the fabp 1 promoter construct with WY14643 resulted in a bell-shaped CRC for fabp1 promoter activity (Table 2, Fig. 6a). Co-treatment with WY14643 and T0070907 did not change CRC of spotted gar fabp1 promoter activity (Table 2, Fig. 6a). Cotreatment with WY14643 and GW6471 abolished the 
Table 1 Pharmacological characterization of PPAR induction of zebrafish fabp $1 a$ and fabp $1 b .1$ promoter activity

\begin{tabular}{|c|c|c|c|c|c|c|c|c|c|c|}
\hline \multicolumn{11}{|l|}{ fabpla } \\
\hline & \multicolumn{5}{|l|}{ WY14643 } & \multicolumn{5}{|l|}{ Rosiglitazone } \\
\hline & - & GW6471 & T0070907 & $\Delta 5^{\prime} F R$ & $\Delta \mathrm{DR} 1$ & - & GW6471 & T0070907 & $\Delta 5^{\prime} F R$ & $\Delta \mathrm{DR} 1$ \\
\hline$E_{\max }(R L U)$ & $152.80 \pm 3.44$ & $152.00 \pm 7.80$ & $147.90 \pm 5.30$ & $136.7 \pm 11.1^{*}$ & $133.4 \pm 4.94$ & $152.80 \pm 3.43$ & $149.60 \pm 3.66$ & $151.70 \pm 6.22$ & $135.30 \pm 7.11$ & $144.40 \pm 2.67$ \\
\hline $\mathrm{EC}_{50}(\mu \mathrm{M})$ & $0.26(0.28-0.23)$ & $15.7(9.32-26.5)^{*}$ & $0.30(0.20-0.44)$ & $1.08(0.71-6.70)^{*}$ & $11.9(9.39-14.3)^{*}$ & $0.32(0.30-0.34)^{* * *}$ & $0.31(0.24-0.41)^{* * *}$ & $2.47(1.59-3.83)^{* * * * * *}$ & $10.6(2.67-4.19)^{* *}$ & $\begin{array}{l}31.8 \\
(17.1-43.6)^{* *},{ }^{* * *}\end{array}$ \\
\hline \multicolumn{11}{|l|}{ fabplb.1 } \\
\hline & \multicolumn{5}{|l|}{ WY14643 } & \multicolumn{5}{|l|}{ Rosiglitazone } \\
\hline & - & GW6471 & T0070907 & $\Delta 5^{\prime} F R$ & $\Delta \mathrm{DR} 1$ & - & GW6471 & T0070907 & $\Delta 5^{\prime} F R$ & $\Delta \mathrm{DR} 1$ \\
\hline$E_{\max }(R L U)$ & $152.30 \pm 5.57$ & $151.30 \pm 4.91$ & $148.7 \pm 5.27$ & $146.4 \pm 3.52$ & $152.80 \pm 7.24$ & $152.30 \pm 5.67$ & $148.30 \pm 4.87$ & $150.70 \pm 7.96$ & $147.80 \pm 2.02$ & $178.50 \pm 8.68^{* *}$ \\
\hline $\mathrm{EC}_{50}(\mu \mathrm{M})$ & $0.29(0.17-0.49)$ & $1.08(0.86-1.54)^{*}$ & $0.10(0.07-0.19)$ & $0.67(0.48-0.95)$ & $28.8(17.3-48.1)^{*}$ & $0.11(0.07-0.15)^{* * *}$ & $0.11(0.08-0.15)^{* * *}$ & $2.40(1.39-4.15)^{* * * * * *}$ & $0.70(0.56-0.89)^{* *}$ & $54.5(32.9-90.4)^{* *}$ \\
\hline
\end{tabular}



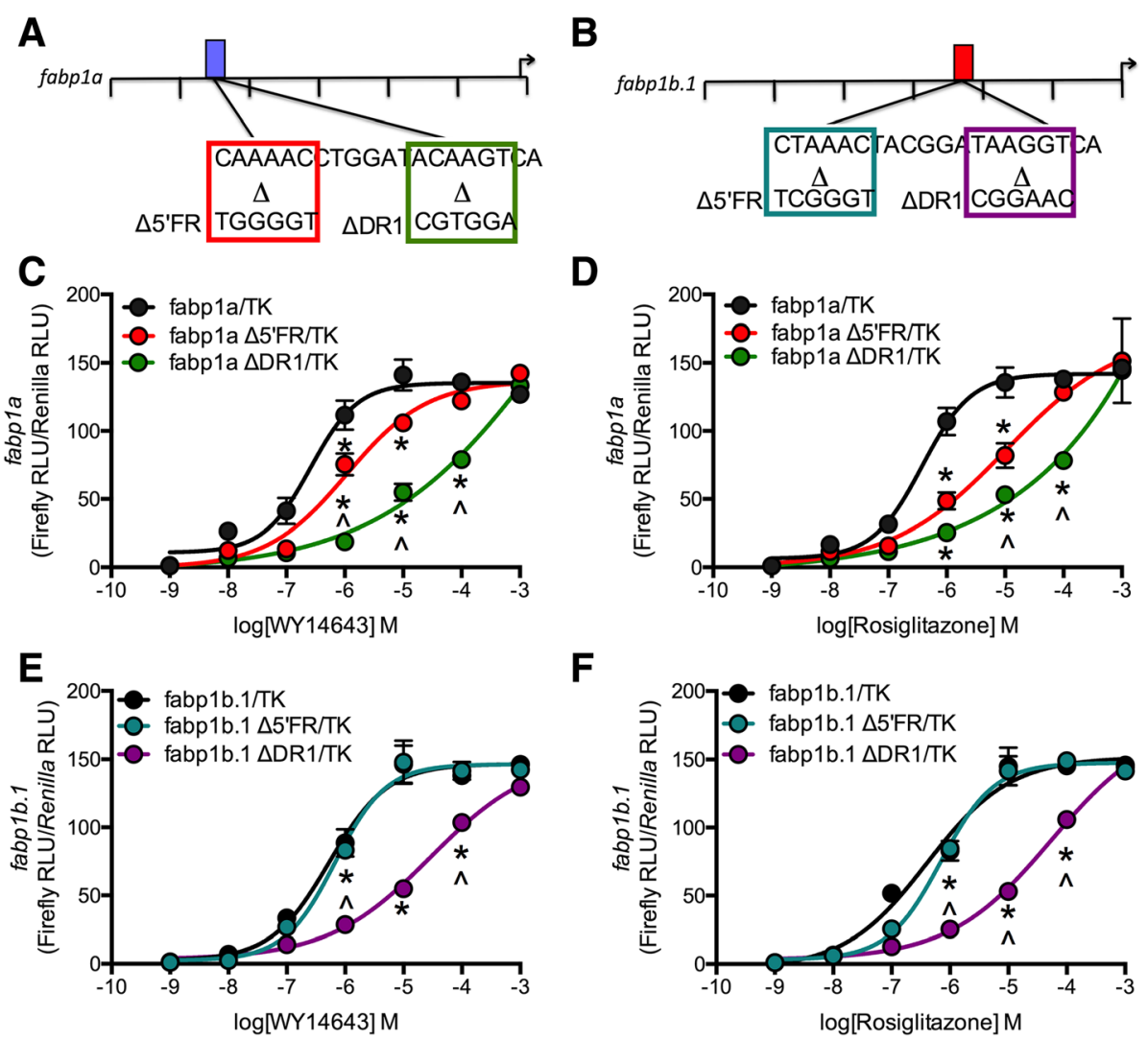

Fig. 5 PPRE mutagenesis identified sites for PPARa- and PPARy-selective induction of zebrafish fabpla and fabp $1 b .1$ promoter activity, respectively. Site-directed mutagenesis was used to alter the $5^{\prime}$ flanking region ( $\left.\triangle 5^{\prime} F R\right)$ or direct repeat element ( $\left.\triangle \mathrm{DR} 1\right)$ PPAR binding sites in the fabp $1 a(\mathbf{a})$ and fabp1b.1 (b) promoter fragments. Firefly luciferase activity driven by the fabpla (c, d) or fabp1b.1 (e, f) promoters was normalized to Renilla luciferase activity driven by the TK promoter in HEK293A cells treated with $1 \mathrm{nM}-1 \mathrm{mM}$ WY14643 (PPARa agonist) (c, e) or rosiglitazone (PPARY agonist) (d, f) for $24 \mathrm{~h}$. Data are mean \pm SD. ${ }^{*} P<0.001$ compared to fabpla/TK or fabp $16.1 / T K$ alone, $\wedge P<0.001$ compared to fabpla $\Delta 5^{\prime} F R / T K$ or fabp1b.1 $\Delta 5^{\prime} \mathrm{FR} / \mathrm{TK}$ within agonist dose as determined via two-way ANOVA followed by Bonferroni's post-hoc test. $n=3$

Table 2 Pharmacological characterization of PPAR agonist and antagonist regulation of spotted gar fabp1 promoter activity

\begin{tabular}{|c|c|c|c|c|c|c|}
\hline & \multicolumn{6}{|l|}{ WY14643 } \\
\hline & \multicolumn{3}{|l|}{ Upward Slope } & \multicolumn{3}{|l|}{ Downward Slope } \\
\hline & - & GW6471 & T0070907 & - & GW6471 & T0070907 \\
\hline$E_{\max }(R L U)$ & $80.6 \pm 7.40$ & $97.5 \pm 3.78$ & $74.2 \pm 9.63$ & - & - & - \\
\hline$E_{\min }(\mathrm{RLU})$ & $10.9 \pm 4.64$ & $8.86 \pm 3.50$ & $8.93 \pm 4.72$ & $24.7 \pm 4.88^{* *}$ & - & $21.6 \pm 4.13^{* *}$ \\
\hline \multirow[t]{4}{*}{$\mathrm{EC}_{50}(\mu \mathrm{M})$} & $0.12(0.07-0.28)$ & $0.54(0.43-0.65)^{*}$ & $0.17(0.05-0.25)$ & $0.69(0.52-1.1)^{* *}$ & - & $0.45(0.22-0.71)^{* *}$ \\
\hline & \multicolumn{6}{|l|}{ Rosiglitazone } \\
\hline & \multicolumn{3}{|l|}{ Upward Slope } & \multicolumn{3}{|l|}{ Downward Slope } \\
\hline & - & GW6471 & T0070907 & - & GW6471 & T0070907 \\
\hline$E_{\max }(R L U)$ & $56.3 \pm 2.40$ & $57.4 \pm 2.44$ & $42.5 \pm 4.50$ & - & - & - \\
\hline$E_{\min }(R L U)$ & $5.28 \pm 4.80$ & $-0.42 \pm 2.73$ & $1.21 \pm 7.80$ & - & - & - \\
\hline $\mathrm{EC}_{50}(\mu \mathrm{M})$ & $0.009(0.006-0.017)$ & $0.016(0.012-0.021)$ & $0.024(0.021-0.062)^{*}$ & - & - & - \\
\hline
\end{tabular}

Data derived from Fig. 6 presented as the mean \pm SEM or $95 \%$ confidence intervals (brackets)

${ }^{*} P<0.05$ compared to agonist treatment alone within the upward slope

${ }^{*} P<0.05$ compared to matched treatment between upward and downward slopes, as determined via two-way ANOVA followed by Bonferroni's post-hoc analysis for $E_{\max }, E_{\min }$ or by non-overlapping confidence intervals $\left(\mathrm{EC}_{50}\right) . n=3-4$ 

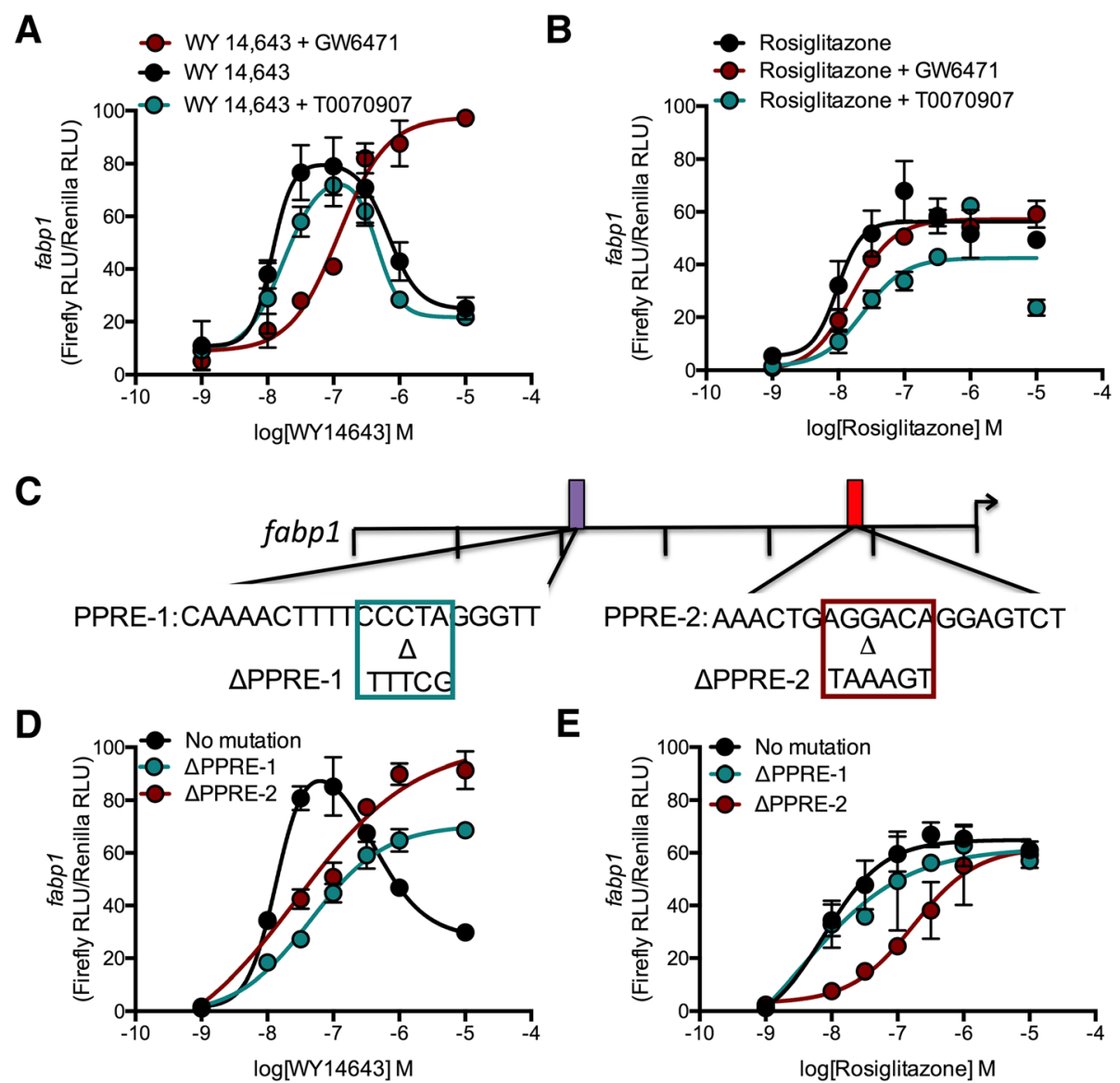

Fig. 6 PPAR induction of the spotted gar fabp 1 promoter was PPARa- and PPARY-selective. a,b) Firefly luciferase activity driven by the fapb1 promoter normalized to Renilla luciferase activity driven by the TK promoter in HEK293A cells treated with $1 \mathrm{nM}-10 \mu \mathrm{M}$ WY14643 (PPARa agonist) (a) or rosiglitazone (PPARy agonist) (b) $\pm 240 \mathrm{nM}$ GW6471 (PPARa antagonist) or $10 \mathrm{nM}$ T0070907 (PPARy antagonist) for 24 h. C) Site-directed mutagenesis was used to alter the DR1 PPAR binding sites of two fabp 1 PPREs at $-1,953$ bp (APPRE-1) or -539 bp ( $\triangle$ PPRE-2). d, e) Firefly luciferase activity driven by the fapb1 'No mutation', $\triangle$ PPRE-1, or $\triangle \mathrm{PPRE}-2$ promoters normalized to Renilla luciferase activity driven by the TK promoter in HEK293A cells treated with $1 \mathrm{nM}-10 \mu \mathrm{M}$ WY14643 (d) or rosiglitazone (e). Data are mean \pm SD. * $P<0.001$ compared to agonist alone or 'No mutation', as determined via two-way ANOVA followed by Bonferroni's post-hoc test. $n=3-4$

bell-shape of the fabp1 CRC and shifted the slope of the CRC to the right compared to the upward slope of the WY14643 CRC (Table 2, Fig. 6a). In contrast to WY14643, treatment of HEK293A cells (transfected with the fabp 1 promoter) with rosiglitazone resulted in a concentration-dependent increase in $f a b p 1$ promoter activity (Table 2, Fig. 6b). The CRC for fabp 1 promoter activity in cells treated with rosiglitazone was not changed by co-treatment with GW6471, but was shifted to the right by co-treatment with T0070907 (Table 2, Fig. 6b). Based on the results of these functional assays, we conclude that spotted gar fabp 1 promoter activity was inducible by both PPAR $\alpha$ and PPAR $\gamma$. However, higher concentrations of WY14643 (PPAR $\alpha$ agonist), but not rosiglitazone (PPAR $\gamma$ agonist), reduced promoter activity of the spotted gar fabp1 genes suggesting an inhibitory effect of PPAR $\alpha$. This inhibitory effect of the PPAR $\alpha$ agonist may be mediated by recruitment of a transcriptional repressor to the PPRE-bound PPAR $\alpha$. Alternatively, this inhibitory effect may be mediated by steric hindrance of PPAR $\alpha$ (i.e. a non-specific crossactivation of PPAR $\gamma$ at high concentrations of WY1463).

The two putative PPREs were identified in the spotted gar fabp 1 promoter region, one located at $-1,953$ bp $5^{\prime}$ upstream of the TSS (PPRE-1), a location similar to the functional PPRE identified in the zebrafish fabpla, and a second PPRE located at -539 bp (PPRE-2), in approximately the same location of a functional PPRE identified in the zebrafish fabp1b.1 promoter. Site-directed mutagenesis was used to confirm the functionality of these putative PPREs in the spotted gar fabp 1 gene. The DR1 regions of the PPRE-1 and PPRE-2 were individually mutagenized ( $\triangle$ PPRE-1, $\triangle$ PPRE-2); both mutagenized PPREs reduced PPAR-induced promoter activity of the spotted gar fabp 1 promoter (Fig. 6c) [16, 17]. $\triangle$ PPRE-1 or $\triangle$ PPRE-2 of the spotted gar fabp1 abolished the bell- 
shaped CRC of promoter activity observed following WY14643 treatment of the transfected HEK293A cells (Table 3, Fig. 6d). $\triangle$ PPRE-1 or $\triangle$ PPRE-2 of fabp1 also shifted either curve to the right compared to the upward slope of the non-mutated fabp 1 promoter (Table 3, Fig. 6d). WY14643 induced spotted gar $\triangle$ PPRE-1 fabp1 promoter activity much more than the promoter activity of the spotted gar $\triangle \mathrm{PPRE}-2$ fabp 1 promoter activity (Table 3, Fig. 6d). The $\triangle$ PPRE-2 fabp1 promoter rosiglitazone CRC was shifted to the right compared to the non-mutated fabp1 promoter (Table 3, Fig. 6e). The $\triangle$ PPRE-1 fabp 1 promoter and non-mutated fabp 1 promoter displayed similar responses to rosiglitazone (Table 3, Fig. 6e). We conclude from these functional promoter assays using the PPAR $\alpha$ - and the PPAR $\gamma$ specific agonists, that PPRE-1 on the spotted gar fabp 1 promoter was PPAR $\alpha$-selective and mediated both increases (concentrations of PPAR agonist $<100 \mathrm{nM}$ ) and decreases (concentrations of PPAR agonist $>100 \mathrm{nM}$ ) in promoter activity. PPRE-2 was PPAR $\gamma$-selective.

\section{Discussion}

In this study, we employed a pharmacological approach to define the PPAR selectivity, potency, and efficacy of PPAR-dependent regulation in the promoters of the zebrafish fabp 1a, fabp $1 b .1$ and fabp $1 b .2$ genes. We observed that the zebrafish fabp 1 a promoter contained a functional, PPAR $\alpha$-selective PPRE, while the zebrafish fabp $1 b .1$ promoter contained a functional, PPAR $\gamma$-selective PPRE. The spotted gar fabpl promoter contained two functional PPREs: a PPAR $\alpha$-selective PPRE (PPRE-1) and a PPAR $\gamma$ selective PPRE (PPRE-2). These results are consistent with previously published conclusions that: (1) the steady-state level of fabpla and fabp1b.1 mRNA and hnRNA levels are induced in adult zebrafish fed a linolenic acid- or clofibrate-rich diets, and this transcriptional activation is mediated by PPAR $[14,15]$, and (2) that the fabpla and fabp1b.1 promoters are functionally-selective for PPAR $\alpha$ and PPAR $\gamma$, respectively as described here and in a previous report [7].

The spotted gar fabp 1 promoter served as a representative of the ancestral $f a b p 1$ gene that gave rise to $f a b p 1 a$ and $f a b p 1 b$ following the teleost WGD [9]. The two functional PPREs identified in the spotted gar fabp 1 promoter were oriented such that PPRE- 1 was PPAR $\alpha$ selective and PPRE-2 was PPAR $\gamma$-selective. Pharmacological analyses and site-directed mutagenesis demonstrated that both the spotted gar PPRE- 1 of fabp 1 and the similarly-aligned zebrafish PPRE of fabpla (Fig. 1) were more responsive to PPAR $\alpha$-agonists and antagonists than to PPAR $\gamma$-agonists and antagonists, based on promoter activity assays, suggesting that the fabpla PPRE at $-1,953$ bp was derived from the PPAR $\alpha$ selective PPRE-1 in the ancestral fabp 1 prior to the teleost WGD. Furthermore, pharmacological analyses and site-directed mutagenesis demonstrated that both the PPRE-2 of spotted gar fabp 1 and the similarly-aligned zebrafish PPRE of fabp1b.1 (Fig. 1) were both more responsive to PPAR $\gamma$ agonists and antagonists than to PPAR $\alpha$ agonists and antagonist as assayed by the induction of promoter activity, suggesting that the fabplb.1 PPRE at -539 bp was derived from an ancestral PPAR $\gamma$-selective PPRE-2 present in the spotted gar (ancestral) fabp1 gene prior to its duplication following the teleost WGD.

Previous studies have focused on non-quantitative or semi-quantitative data derived from electrophoretic mobility shift assays to determine the specificity of PPARs interaction with PPREs [16-18, 22]. The unique pharmacological approach used in this study to define the

Table 3 Pharmacological characterization of spotted gar fabp1 promoter PPRE mutants

\begin{tabular}{|c|c|c|c|c|c|c|}
\hline & \multicolumn{6}{|l|}{ WY14643 } \\
\hline & \multicolumn{3}{|l|}{ Upward Slope } & \multicolumn{3}{|l|}{ Downward Slope } \\
\hline & No mutation & $\triangle \mathrm{PPRE}-1$ & $\triangle \mathrm{PPRE}-2$ & No mutation & $\triangle \mathrm{PPRE}-1$ & $\triangle \mathrm{PPRE}-2$ \\
\hline$E_{\max }(R L U)$ & $101 \pm 2.56$ & $70.6 \pm 2.17^{*}$ & $102 \pm 8.65$ & - & - & - \\
\hline$E_{\min }(R L U)$ & $1.32 \pm 2.91$ & $-1.64 \pm 3.08$ & $-17.4 \pm 18.2$ & $27.6 \pm 4.76^{* *}$ & - & - \\
\hline \multirow[t]{4}{*}{$\mathrm{EC}_{50}(\mu \mathrm{M})$} & $0.013(0.004-0.023)$ & $0.045(0.032-0.064)^{*}$ & $0.028(0.008-0.098)$ & $0.38(0.20-0.41)^{* *}$ & - & - \\
\hline & \multicolumn{6}{|l|}{ Rosiglitazone } \\
\hline & \multicolumn{3}{|l|}{ Upward Slope } & \multicolumn{3}{|l|}{ Downward Slope } \\
\hline & No mutation & $\triangle P P R E-1$ & $\triangle \mathrm{PPRE}-2$ & No mutation & $\triangle P P R E-1$ & $\Delta$ PPRE-2 \\
\hline$E_{\max }(R L U)$ & $64.9 \pm 2.34$ & $61.9 \pm 6.66$ & $62.1 \pm 5.07$ & - & - & - \\
\hline$E_{\min }(R L U)$ & $-7.47 \pm 3.79$ & $1.17 \pm 0.05$ & $2.94 \pm 4.03$ & - & - & - \\
\hline $\mathrm{EC}_{50}(\mu \mathrm{M})$ & $0.008(0.003-0.019)$ & $0.003(0.001-1.34)$ & $0.18(0.08-0.36)^{*}$ & - & - & - \\
\hline
\end{tabular}


regulation and its evolution of promoter activity provided quantitative data, which supports the contention that the 5'FR is directly involved in PPAR $\alpha-$, but not PPAR $\gamma^{-}$, dependent promoter activation [17]. Furthermore, this work supports earlier findings that the DR1 regulates general PPAR-dependent promoter activation [16-18, 22].

The data reported here raise two questions. First, how did the divergent transcriptional regulation of the zebrafish fabpla, fabp1b.1, and fabp $1 b .2$ genes by PPARs arise? Second, why was this divergent regulation of fabp 1a, fabp1b.1, and fabp1b.2 by PPARs not selected against? To answer these questions, we must consider the data from this study and how it might be integrated into the existing model of gene duplication, particularly in teleost fishes. The spotted gar fabp1 gene, used here as a surrogate for the ancestral fabp 1 gene promoter, contained at least two functional PPREs that resembled the zebrafish fabpla and fabp $1 b .1$ promoter PPREs, respectively, in both their location relative to the TSS, and their PPAR-isoform selectivity. The existing model of gene duplication in teleosts suggests that zebrafish fabpla and ancestral fabp $1 b$ genes arose by WGD [9, 12, 14], whereas the zebrafish fabp $1 b .1$ and fabp $1 b .2$ arose by tandem duplication of the fabp $1 b$ gene during misaligned unequal crossing over during meiosis [12]. From these data, we can construct a model for divergent regulation of the fabp1 genes within the context of the DDC model (Fig. 7) [2-4]. The most straightfoward explanation for the retention of fabp 1a, fabp1b.1 and fabp1b.2 in the zebrafish genome is the ancestral teleost fabp1 gene was duplicated during a WGD event, which was later followed by a tandem duplication specific to zebrafish. We showed here that increasing concentrations of the PPAR $\alpha$-selective agonist, WY14643, enhanced and then repressed spotted gar fabp1 promoter activity (Fig. 6). While one might invoke recruitment of a transcriptional repressor of the spotted gar fabp1 promoter activity, this is not the most parsimonious explanation. Elimination of either PPRE-1 or PPRE-2 abolished the biphasic response of spotted gar fabp1 promoter activity suggesting PPAR $\alpha$-dependent functional antagonism of the spotted gar fabpl promoter activity, which occurred via an interaction or competition between the two identified functional PPREs (Fig. 6). No functional antagonism was observed in the zebrafish fabp1a and fabp1b.1 promoters (Fig. 5). We suggest that following the teleost WGD, mutations may have accumulated independently in the PPAR $\alpha$-selective PPRE of the zebrafish fabpla promoter, and in the PPAR $\gamma$-selective PPRE of the zebrafish $f a b p 1 b$ promoter, leading to elimination of these elements in their respective promoters and loss of the functional antagonism observed in the spotted gar fabp 1 promoter (Fig. 7). Zebrafish fabp $1 a$ and fabp $1 b$ promoters, therefore, underwent subfunctionalization relative to $f a b p 1$ with regard to PPAR isoform specificity. Subsequent tandem duplication of the zebrafish fabp $1 b$ gene resulted in a PPAR $\gamma$-selective PPRE in fabp $1 b .1$ and the loss of a functional PPRE in the zebrafish fabp $1 b .2$ promoter with retention of basal promoter activity (Fig. 7) [7]. Zebrafish is unique among teleosts for having three fabp1 genes [12]. These data demonstrate that fabpla and fabp1b.1 genes have retained their functional regulation by PPAR, and therefore their association with PPARdependent metabolic and hormonal signaling pathways [16]. In contrast, the local (tandem) duplicate fabp1b.2 is retained in the genome, but its transcription is not modulated by either dietary fatty acids or PPAR agonists. As such, the zebrafish fabp1b.2 gene does not appear to be

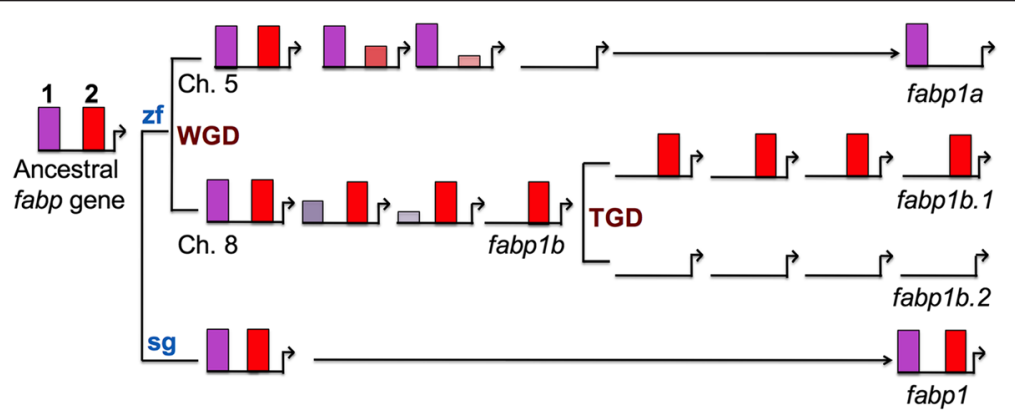

Time \& accumulation of mutations

Fig. 7 PPAR subfunctionalization of the fabp 1 promoters following the teleost whole genome duplication. An ancestral fabp 1 promoter contained two PPREs that had high sequence identity to the consensus sequence for PPREs. These PPREs were retained in the spotted gar fabpl gene promoter. In zebrafish, fabp $1 a$ and the ancestral fabp $1 b$ underwent subfunctionalization. fabp $1 a$ retained the PPARa-selective PPRE and fabp $1 b$ retained the PPARY-selective PPRE, following whole genome duplication. Further subfunctionalization of promoter function occurred following the tandem gene duplication of zebrafish fabp 16 resulting in fabp 16.1 and fabp 1b.2. Passage of time and accumulation of mutations is represented from left to right. PPREs are represented by purple $(\mathbf{1}, a)$ or red $(\mathbf{2}, \gamma)$ rectangles. PPRE loss is represented by smaller, more transparent rectangles. $\mathbf{z f}$, zebrafish; sg, spotted gar; WGD, whole genome duplication; TGD, tandem gene duplication 
associated with PPAR-dependent physiological processes $[7,12,14]$. This conclusion is consistent with cross-species analyses that have shown genes retained from WGD events often belong to signalling networks, whereas local gene duplication events are more likely to acquire network-independent functions [23, 24]. Additional research is required to understand what other regulatory elements have undergone neo-, non-, or subfunctionalization in the zebrafish fabp 1 promoters compared to the spotted gar fabp1 promoter [3, 4, 25-28]. Our observations provide an example of increasing intra-organismal complexity through the subfunctionalization of response to PPAR stimuli among gene duplicates.

\section{Conclusions}

The present subfunctionalized state of PPAR responsiveness in the zebrafish fabpla, fabp1b.1, and fabp $1 b .2$ promoters may represent a form of segregation avoidance such that three gene products sharing similar function are expressed in different tissues, under different developmental or environment conditions [27, 28]. These data demonstrate the divergent, PPAR isoform-specific regulation of zebrafish fabpla, fabp1b.1, and fabp1b.2 in relation to their subfunctionalization across evolutionary history using a unique pharmacological approach.

\section{Methods}

\section{Zebrafish and spotted gar fabp 1 promoter sequences}

Promoter sequences for zebrafish fabpla, fabp 1b.1, and fabp $1 b .2$ and spotted gar fabp1 genes were obtained using the CNS Discovery Pipeline (v. 3.0) created and described by Turco et al. [19]. The source code for the CNS Discovery Pipeline 3.0 is available for download at https://github.com/gturco/find_cns with instructions for installation at (https://github.com/gturco/find_cns/blob/ master/INSTALL.rst) [19]. CNS Discovery Pipeline was run using default settings except that the filter for promoter regions containing gene-coding regions was removed. The input was the zebrafish $\mathrm{Zv} 9$ whole genome assembly (GenBank Assembly ID GCA_000002035.2) and spotted gar Linkage group LG2 LepOcu1 representative genome assembly (GenBank Assembly ID GCA_000242695.1, Gene symbol LOC102694982) [29]. The length of promoter fragments retrieved by the CNS discovery pipeline was determined as the region within 4,000 bp $5^{\prime}$ of the TSS containing $>60 \%$ sequence identity to the consensus of vertebrate transcription factor binding motifs [19]. The resulting "fasta" output files for the fabp promoters and their corresponding genes were used to design PCR primers to clone $f a b p$ promoter fragments (Additional file 1).

\section{Identification of putative PPREs in teleost fabp1 promoters by in silico analysis}

Promoter sequences were analyzed for putative PPREs using MatInspector (v. 8.1) with the Genomatix ElDorado genomes database and the vertebrate matrix group. The PPRE was defined as 5'-CAAAACTAGGTCANAGG TCA-3' [16-18]. The mismatch threshold was set to $35 \%$ (i.e. transcription factor sites were identified if they were $65 \%$ similar to the corresponding IUPAC string).

\section{Cell culture}

Primary zebrafish cell culture methods were adapted from Kan et al. [30]. Primary explant cell cultures of zebrafish liver and intestine were obtained from adult male fish. Fish were euthanized with tricaine $(10 \% \mathrm{v} / \mathrm{v})$ and rinsed with $70 \%$ ethanol in sterile phosphatebuffered saline (PBS). The liver and intestine were dissected, rinsed once with PBS, and incubated in $0.25 \%$ trypsin-EDTA (Gibco, Oakville, ON) for $5 \mathrm{~min}$ at room temperature. Tissue was suspended in trypsin-EDTA by pipette and centrifuged at $500 \mathrm{x} \mathrm{g}$ for $5 \mathrm{~min}$ at room temperature. Cells were resuspended in media containing 50 \% Leibovitz's L-15, 35 \% high glucose DMEM, 15 \% Ham's F-12, 5 \% FBS, $0.15 \mathrm{~g} / \mathrm{L}$ sodium bicarbonate, $15 \mathrm{mM}$ HEPES, $0.01 \mathrm{mg} / \mathrm{mL}$ bovine insulin, and $50 \mathrm{ng} /$ $\mathrm{mL}$ human EGF (Gibco) and maintained $28{ }^{\circ} \mathrm{C}, 100 \%$ atmospheric air on poly-D-lysine-coated cell culture plates. Primary zebrafish cells were maintained for $48 \mathrm{~h}$ prior to drug treatment. Media was changed daily. All protocols were in accordance with the guidelines outlined by the Canadian Council on Animal Care. All animal protocols were approved by the Carleton Animal Care Committee at Dalhousie University prior to start of this study.

Human embryonic kidney 293A (HEK293A) cells were obtained from Cedarlane (Burlington, ON). HEK293A cells were maintained at $37{ }^{\circ} \mathrm{C}, 5 \% \mathrm{CO}_{2}$ in DMEM containing $10 \% \mathrm{FBS}$ and $10^{4} \mathrm{U} / \mathrm{mL}$ Pen/Strep. HEK293A cells express PPAR $\alpha$ and $\gamma$ [31], which was confirmed by sequencing the RT-PCR products (data not shown).

\section{Cloning of zebrafish fabp $1 a$, fabp $1 b .1$, and fabp 1b.2, and spotted gar fabp1 promoter fragments into the pGL3- basic plasmid}

DNA fragments containing the zebrafish fabpla, fabp $1 b .1$ and $f a b p 1 b .2$, and spotted gar fabp 1 promoter region were amplified from genomic DNA by PCR. Genomic DNA was isolated from frozen liver using the GenElute Genomic DNA Miniprep kit according to the manufacturer's instructions (Sigma-Aldrich, Oakville, ON). The PCR contained: $2 \mathrm{mM} \mathrm{MgCl} 2,0.5 \mu \mathrm{M}$ forward and reverse primers (Additional file 2), $0.3 \mathrm{mM}$ dNTPs, $1 \mathrm{U}$ Taq DNA polymerase, and $40 \mathrm{ng}$ genomic DNA. PCR conditions were: $95{ }^{\circ} \mathrm{C}$ for $10 \mathrm{~min}$; 35 cycles of $95{ }^{\circ} \mathrm{C}$ for 
$30 \mathrm{~s}, 57^{\circ} \mathrm{C}$ for $30 \mathrm{~s}, 72{ }^{\circ} \mathrm{C}$ for $6 \mathrm{~min}$; and $72{ }^{\circ} \mathrm{C}$ for $10 \mathrm{~min}$. PCR products were resolved by gel electrophoresis and purified using the GenElute Gel Extraction kit (Sigma-Aldrich). Purified fabpla, fabp1b.1, and fabp1b.2 PCR products were digested with MluI and HindIII according to the manufacturer's instructions (Fermentas, Burlington, $\mathrm{ON})$. The purified spotted gar fabp1 PCR product was ligated into pGEM-T easy vector (Fermentas) at $16{ }^{\circ} \mathrm{C}$ overnight using T4 DNA ligase according to the manufacturer's instructions (Invitrogen, Burlington, ON). The spotted gar fabp1 promoter fragment was excised from pGEM-T by digestion with $\mathrm{NcoI}$ and SacI according to the manufacturer's instructions (Fermentas). fabp 1a, fabp 1b.1, and fabp 1b.2 PCR products were ligated into pGL3-Basic (Promega, Madison, WI) at $16{ }^{\circ} \mathrm{C}$ overnight using T4 DNA ligase according to the manufacturer's instructions (Invitrogen). The resulting plasmids (pfabpla, pfabplb.1, $\mathrm{p} f a b p 1 b .2$, and $\mathrm{p} f a b p 1)$ were propagated in ampicillinresistant DH5 $\alpha$ competent E. coli (New England Biolabs, Whitby, $\mathrm{ON}$ ) and purified using the GenElute Plasmid Midiprep kit (Sigma-Aldrich). The pHRL-TK plasmid was obtained from Promega.

$\mathrm{p} f a b p 1 a, \mathrm{p} f a b p 1 b .1$, and $\mathrm{p} f a b p 1$ mutant plasmids were generated by PCR-based site-directed mutagenesis. The pfabpla PPRE 5'FR at $-2,710$ bp was mutated from 5' $5^{\prime}$-CAAAAC-3' to $5^{\prime}$-TGGGGT-3' and the PPRE DR1 at $-2,710$ bp was mutated from $5^{\prime}$ ACAAGT-3' to 5'-CGTGGA-3'. The pfabp1b.1 PPRE $5^{\prime} \mathrm{FR}$ at $-1,232$ bp was mutated from 5'-CTAAAC-3' to $5^{\prime}$-TCGGGT-3' and the PPRE DR1 at $-1,232 \mathrm{bp}$ was mutated from $5^{\prime}$-TAAGGT-3' to $5^{\prime}$-CGGAAC-3'. The pfabp1 PPRE-1 (-1,953 bp) was mutated from $5^{\prime}-$ CCCTA-3' to $5^{\prime}$-TTTCG-3' and PPRE-2 (-539 bp) was mutated from $5^{\prime}$-AGGACA-3' to $5^{\prime}$-TAAAGT-3'. Reactions were composed of $2 \mathrm{mM} \mathrm{MgCl}, 0.5 \mu \mathrm{M}$ forward and reverse mutagenic primers (Additional file 2), $0.3 \mathrm{mM}$ dNTPs, $1 \mathrm{U}$ Taq DNA polymerase, and $40 \mathrm{ng}$ plasmid DNA. PCR conditions were: $95{ }^{\circ} \mathrm{C} 1 \mathrm{~min}, 18$ cycles of $95{ }^{\circ} \mathrm{C} 50 \mathrm{~s}, 60^{\circ} \mathrm{C} 1 \mathrm{~min}$, and $68^{\circ} \mathrm{C} 8 \mathrm{~min}$, followed by a final extension at $68{ }^{\circ} \mathrm{C}$ for $10 \mathrm{~min}$. Input plasmid was removed by digestion with the methylation-insensitive $D p n \mathrm{I}(5 \mathrm{U})$ in $1 \mathrm{X}$ FastDigest Green Buffer ${ }^{\circ}$ in a final volume of $20 \mu \mathrm{L}$ (Fermentas, Burlington, $\mathrm{ON}$ ) for $1 \mathrm{~h}$ at $37^{\circ} \mathrm{C}$. The constructs of wild-type and mutagenized zebrafish and spotted gar promoters was confirmed by DNA sequencing of the promoter-reporter gene constructs prior to transfection of HEK293A cells (data not shown).

Transfection, PPAR agonist and antagonist treatment, and the dual luciferase assay

Transfections of HEK293A cells was performed using lipofectamine 2000 reagent according to the manufacturer's instructions (Invitrogen) with $400 \mathrm{ng}$ of pfabpla, pfabp1b.1, pfabp1b.2, pfabp1, or pGL3-Basic (background control), and $200 \mathrm{ng}$ pHRL-TK. The luciferase activity of the pHRL-TK plasmid containing the Renilla luciferase gene under the regulation of the cytomegalovirus thymidine kinase (TK) promoter was used to normalize firefly luciferase activity under the regulation of zebrafish promoters. Luciferase activity was quantified according to the manufacturer's instructions (Promega).

HEK293A and primary zebrafish cells were treated with rosiglitazone (PPARY agonist), WY14643 (PPAR agonist), T0070907 (PPARY antagonist), GW 6471 (PPAR $\alpha$ antagonist), or vehicle (0.5\% DMSO) at the concentrations and times indicated [32, 33]. All PPAR agonists and antagonists were purchased from Sigma-Aldrich.

\section{Quantitative reverse transcriptase PCR}

RNA was extracted from HEK239 cells using Trizol ${ }^{\circ}$ (Invitrogen). Reverse transcription reactions were carried out with SuperScript $\mathrm{III}^{\circ}$ reverse transcriptase $(+\mathrm{RT}$; Invitrogen), or without (-RT) as a negative control for use in subsequent PCR experiments according to the manufacturer's instructions. Two micrograms of RNA were used per RT reaction. qRT-PCR was conducted using the LightCycler system and software (version 3.0; Roche, Laval, QC). Reactions were composed of a primerspecific concentration of $\mathrm{MgCl}_{2}$ (Additional file 2), $0.5 \mu \mathrm{M}$ each of forward and reverse primers (Additional file 2), $2 \mu \mathrm{L}$ of LightCycler ${ }^{\bullet}$ FastStart Reaction Mix SYBR Green $\mathrm{I}$, and $2 \mu \mathrm{L}$ cDNA to a final volume of $20 \mu \mathrm{L}$ with $\mathrm{dH}_{2} \mathrm{O}$ (Roche). The PCR program was: $95^{\circ} \mathrm{C}$ for $10 \mathrm{~min}, 50 \mathrm{cy}$ cles of $95^{\circ} \mathrm{C} 10 \mathrm{~s}$, a primer-specific annealing temperature (Additional file 2) for $5 \mathrm{~s}$, and $72{ }^{\circ} \mathrm{C}$ for $10 \mathrm{~s}$. Experiments always included sample-matched -RT controls, a nosample $\mathrm{dH}_{2} \mathrm{O}$ control, and a standard control containing product-specific cDNA of a known concentration. cDNA abundance was calculated using the ${ }^{\Delta \Delta} \mathrm{CT}$ method and normalized to GAPDH levels [34].

\section{Statistical analyses}

CRCs were fit using non-linear regression analyses [variable slope (four parameters) and Bell-shaped] in GraphPad Prism (v. 5.0). Statistical analyses were conducted by one-way ANOVA followed by Tukey's post-hoc test or two-way ANOVA follow by Bonferroni's post-hoc test, as indicated. Homogeneity of variance was confirmed using Bartlett's test. All results are reported as the mean \pm standard deviation (SD) or standard error of the mean (SEM), as indicated, from at least three independent experiments.

\section{Additional files}

Additional file 1: Conserved non-coding sequence files (fasta) analyzed in this study. Putative PPREs are indicated as green 65-74.9\%, yellow $75-$ $84.9 \%$, orange $>85 \%$ sequence similarly to the defined PPRE consensus 
sequence. Red indicates primer binding sites for PCR. Light blue indicates regions of repetitive TAT sequences. DNA sequences determined by sequencing PCR-cloned promoter fragments of spotted gar or zebrafish genomic DNA. (PDF $38 \mathrm{~kb}$ )

Additional file 2: Table S1. Synthetic oligonucleotides used for cloning fabpl (spotted gar), fabpla (zebrafish), fabp1b.1 (zebrafish), and fabp1b.2 (zebrafish) promoter fragments, mutagenesis of the fabpl, fabpla, and fabp 1b.1 PPREs, and quantification of fabp 1a, fabp 1b.1, and fabp 1b.2 transcripts via $\mathrm{qRT}$-PCR in this study. (PDF $82 \mathrm{~kb}$ )

\section{Abbreviations}

5'FR, 5' flanking region; CNS, conserved non-coding sequence; CRC concentration-response curve; DDC, duplication-degenerationcomplementation; DR1, direct repeat region; fabp, fatty acid-binding protein; HEK, human embryonic kidney cell line; PBS, phosphate-buffered saline; PPAR, peroxisome proliferator-activated receptor; PPRE, peroxisome proliferator-activated receptor response element; RT, reverse transcriptase; SEM, standard error of the mean; SD, standard deviation; sg, spotted gar; TGD, tandem gene duplication; TK, thymidine kinase; TSS, transcription start site; WGD, whole genome duplication; zf, zebrafish

\section{Acknowledgements}

None.

\section{Funding}

This work was supported by an National Sciences and Engineering Research Council Canada (NSERC) Grant to JMW, and a Bridge Funding Grant from Dalhousie University to EMD-W. RBL is supported by studentships from the Canadian Institutes of Health Research (CIHR), the Huntington Society of Canada, Killam Trusts, and Nova Scotia Health Research Foundation. None of these funding bodies influenced the design of the study or the collection, analysis, or interpretation of data presented in the manuscript.

\section{Availability of data and material}

The data sets supporting the results of this article are available in the Dryad repository, [http://dx.doi.org/10.5061/dryad.q03n7] [35].

\section{Authors' contributions}

RBL, EMD-W, and JMW conceived the study. RBL conducted the experiments and analyzed the data. RBL, EMD-W, and JMW contributed to the writing of the manuscript. All authors read and approved the final manuscript.

\section{Authors' information}

RBL is currently a postdoctoral fellow at in the Department of Molecular Therapeutics The Scripps Research Institute, Florida campus. EMD-W is a Professor in the Department of Pharmacology at Dalhousie University. JMW is a Professor in the Department of Biology at Dalhousie University.

\section{Competing interests}

The authors declare that they have no competing interests.

\section{Consent for publication}

Not applicable.

\section{Ethics approval and consent to participate}

All protocols requiring euthanized zebrafish were in accordance with the guidelines detailed by the Canadian Council on Animal Care. Zebrafish animal protocols were approved by the Carleton Animal Care Committee at Dalhousie University prior to beginning the study.

\section{Author details}

'Department of Pharmacology, Dalhousie University, 5850 College St, Halifax, NS B3H 4R2, Canada. ${ }^{2}$ Department of Biology, Dalhousie University, 31355 Oxford St, PO Box 15000, Halifax, NS B3H 4R2, Canada.

Received: 5 February 2016 Accepted: 30 June 2016 Published online: 16 July 2016

\section{References}

1. Zhang J. Evolution by gene duplication: an update. Trends Ecol Evol. 2003; 18:292-8.

2. Force A, Lynch M, Pickett FB, Amores A, Yan YL, Postlethwait J. Preservation of duplicate genes by complementary, degenerative mutations. Genetics. 1999:151:1531-45.

3. Lynch M, Conery JS. The evolutionary fate and consequences of duplicate genes. Science. 2000;290:1151-5.

4. Taylor JS, Raes J. Duplication and divergence: the evolution of new genes and old ideas. Annu Rev Genet. 2004;38:615-43.

5. Holland PW, Garcia-Fernandez J, Williams NA, Sidow A. Gene duplications and the origins of vertebrate development. Dev Suppl. 1994;1994:125-33.

6. Esteves A, Knoll-Gellida A, Canclini L, Silvarrey MC, André M, Babin PJ. Fatty acid-binding proteins have the potential to channel dietary fatty acid into enterocyte nuclei. J Lipid Res. 2015;57:219-32.

7. Laprairie RB, Denovan-Wright EM, Wright JM. Divergent evolution of cisacting peroxisome proliferator-activated receptor elements that control the tandemly-duplicated fatty acid-binding protein genes, fabp $1 \mathrm{~b} .1$ and fabp $1 \mathrm{~b}$. 2 in zebrafish. Genome. 2016;in press doi: 10.1139/gen-2016-0033

8. Robinson-Rechavi M, Marchand O, Escriva H, Bardet PL, Zelus D, Hughes S, Laudet $\mathrm{V}$. Euteleost fish genomes are characterized by expansion of gene families. Genome Res. 2001;11:781-8.

9. Glasauer SMK, Neuhauss SCF. Whole-genome duplication in teleost fishes and its evolutionary consequences. Mol Genet Genomics. 2014;298:1040-60.

10. Hurley IA, Mueller RL, Dunn KA, Schmidt EJ, Friedman M, Ho RK, Prince VE, Yang Z, Thomas MG, Coates MI. A new time-scale for ray-finned fish evolution. Proc Biol Sci. 2007;274:489-98.

11. Santini F, Harmon LJ, Carnevale G, Alfaro ME. Did genome duplication drive the origin of teleosts? A comparative study of diversification in ray-finned fishes. BMC Evol Biol. 2009;9:194.

12. Karanth S, Denovan-Wright EM, Thisse C, Thisse B, Wright JM. Tandem duplication of the fabp $1 b$ gene and subsequent divergence of the tissuespecific distribution of fabp 16.1 and fabp 16.2 transcripts in zebrafish (Danio rerio). Genome. 2009;52:985-92.

13. Brown GR, Hem V, Katz KS, Ovetsky M, Wallin C, Ermolaeva O, et al. Gene: a gene-centered information resource at NCBI. Nucleic Acids Res. 2015; 43(database issue):D36-42.

14. Karanth S, Lall SP, Denovan-Wright EM, Wright JM. Differentia transcriptional modulation of duplicated fatty acid-binding protein genes by dietary fatty acids in zebrafish: evidence for subfunctionailzation and neofunctionalization of duplicated genes. BMC Evol Biol. 2009;9:219.

15. Venkatachalam AB, Lall SP, Denovan-Wright EM, Wright JM. Tissue-specific differential induction of duplicated fatty acid-binding protein genes by the peroxisome proliferator, clofibrate, in zebrafish (Danio rerio). BMC Evol Biol. 2012:12:112.

16. Palmer $\mathrm{CN}, \mathrm{Hsu} \mathrm{MH}$, Griffin HJ, Johnson EF. Novel sequence determinants in peroxisome proliferator signaling. J Biol Chem. 1995;270:16114-21.

17. Hsu MH, Palmer CN, Song W, Griffin KJ, Johnson EF. A carboxyl-terminal extension of the zinc finger domain contributes to the specificity and polarity of peroxisome proliferator-activated receptor DNA binding. J Biol Chem. 1998;273:27988-97.

18. Juge-Aubry C, Pernin A, Favez T, Burger AG, Wahli W, Meier CA, Desvergne B. DNA binding properties of peroxisome proliferator-activated receptor subtypes on various natural peroxisome proliferator response elements. J Biol Chem. 1997;272:25252-9.

19. Turco G, Schnable JC, Pedersen B, Freeling M. Automated conserved noncoding sequence (CNS) discovery reveals differences in gene content and promoter evolution among grasses. Front Plant Sci. 2013;4:170.

20. Kassam A, Hunter J, Rachubinski RA, Capone JP. Subtype- and response element-dependent differences in transactivation by peroxisome proliferator-activated receptors alpha and gamma. Mol Cell Endocrinol. 1998;141:153-62.

21. Bugge A, Mandrup S. Molecular Mechanisms and Genome-Wide Aspects of PPAR Subtype Specific Transactivation. PPAR Res. 2010;2010:169506.

22. Wolfrum C, Borrmann CM, Börchers T, Spener F. Fatty acids and hypolipidemic drugs regulate peroxisome proliferator-activated receptors aand g-mediated gene expression via liver fatty acid binding protein: A signaling path to the nucleus. Proc Natl Acad Sci U S A. 2001;98:2323-8.

23. Carretero-Paulet $L$, Fares MA. Evolutionary dynamics and functional specialization of plant paralogs formed by whole and small-scale genome duplications. Mol Biol Evol. 2012;29:3541-51. 
24. Fares MA, Keane OM, Toft C, Carretero-Paulet L, Jones GW. The Roles of Whole-Genome and Small-Scale Duplications in the Functional Specialization of Saccharomyces cerevisiae Genes. PLoS Genet. 2013;9: e1003176.

25. Smathers RL, Peterson DR. The human fatty acid-binding protein family: evolutionary divergences and functions. Hum Genomics. 2011:5:170-91.

26. Ohno S. Evolution by gene duplication. Berlin: Springer; 1970.

27. Woods IC, Wilson C, Frielander B, Chang P, Reyes DK, Nix R, et al. The zebrafish gene map defines ancestral vertebrate chromosomes. Genome Res. 2005;15:1307-14.

28. Conrad B, Antonarakis SE. Gene duplication: a drive for phenotypic diversity and cause of human disease. Ann Rev Genomics Hum Genet. 2007;8:17-35.

29. Benson DA, Cavanaugh M, Clark K, Karsch-Mizrachi I, Lipman DJ, Ostell J, Sayers EW. GenBank. Nucleic Acids Res. 2013;41(database issue):D36-42.

30. Kan NG, Junghans $\mathrm{D}$, Belmonte JCl. Compensatory growth mechanisms regulated by BMP and FGF signaling mediate liver regeneration in zebrafish after partial hepatectomy. FASEB J. 2009;23:3516-26.

31. Zagranichnaya TK, Wu X, Danos AM, Villereal ML. Gene expression profiles in HEK-293 cells with low or high store-operated calcium entry: can regulatory as well as regulated genes be identified? Physiol Genomics. 2005;21:14-33.

32. Lehmann JM, Moore LB, Smith-Oliver TA, Wilkison WO, Willson TM, Kliewer SA. An antidiabetic thiazolidinedione is a high affinity ligand for peroxisome proliferator-activated receptor gamma (PPAR gamma). J Biol Chem. 1995; 270:12953-6.

33. Keller $H$, Devchand PR, Perroud M, Wahli W. PPAR alpha structure-function relationships derived from species-specific differences in responsiveness to hypolipidemic agents. Biol Chem. 1997;378:651-5.

34. Livak KJ, Schmittgen TD. Analysis of relative gene expression data using real-time quantitative PCR and the 2(-Delta Delta C(T)) Method. Methods. 2001;25:402-8

35. Laprairie RB, Denovan-Wright EM, Wright JM. Data from:

Subfunctionalization of peroxisome proliferator response elements accounts for retention of duplicated fabp 1 genes in zebrafish. 2016. Dryad Digital Repository, http://dx.doi.org/10.5061/dryad.q03n7.

36. Brown GR, Hem V, Katz KS, Ovetsky M, Wallin C, Ermolaeva O, Tolstoy I, Tatusova T, Pruitt KD, Maglott DR, Murphy TD. Gene: a gene-centered information resource at NCBI. Nucleic Acids Res. 2015:43:D36-42.

\section{Submit your next manuscript to BioMed Central and we will help you at every step:}

- We accept pre-submission inquiries

- Our selector tool helps you to find the most relevant journal

- We provide round the clock customer support

- Convenient online submission

- Thorough peer review

- Inclusion in PubMed and all major indexing services

- Maximum visibility for your research

Submit your manuscript at www.biomedcentral.com/submit 